\title{
OPEN A high-efficiency and stable perovskite solar cell fabricated in ambient air using a polyaniline passivation layer
}

\author{
Dong In Kim ${ }^{1}$, Ji Won Lee ${ }^{1,2}$, Rak Hyun Jeong ${ }^{1,2}$ \& Jin-Hyo Boo ${ }^{1,2 \bowtie}$
}

Over the past number of years, the power conversion efficiency of perovskite solar cells has remained at $\mathbf{2 5 . 5 \%}$, reflecting a respectable result for the general incorporation of organometallic trihalide perovskite solar cells. However, perovskite solar cells still suffer from long-term stability issues. Perovskite decomposes upon exposure to moisture, thermal, and UV-A light. Studies related to this context have remained ongoing. Recently, research was mainly conducted on the stability of perovskite against non-radiative recombination. This study improved a critical instability in perovskite solar cells arising from non-radiative recombination and UV-A light using a passivation layer. The passivation layer comprised a polyaniline (PANI) polymer as an interfacial modifier inserted between the active layer and the electron transport layer. Accordingly, the UV-A light did not reach the active layer and confined the $\mathrm{Pb}^{2+}$ ions at PANI passivation layer. This study optimized the perovskite solar cells by controlling the concentration, thickness and drying conditions of the PANI passivation layer. As a result, the efficiency of the perovskite solar cell was achieved $15.1 \%$ and showed over $84 \%$ maintain in efficiency in the ambient air for one month using the $65 \mathrm{~nm}$ PANI passivation layer.

The field of solar cells, which is attracting attention as a renewable energy source, requires low-cost, high-efficiency, and stability characteristics. The performance of silicon solar cells is close to its theoretical limit and has high stability. Nevertheless, it is difficult to apply these cells to electronics, clothing, and construction products that have many curves and transparent characteristics. To overcome this, organic solar cells and dye-sensitized solar cells have been studied. However, limitation related to their efficiency, stability, and durability remain. Perovskite material has an $\mathrm{ABX}_{3}$ crystal structure. The A site cation is $\mathrm{CH}_{3} \mathrm{NH}_{3}$, the $\mathrm{B}$ site cation is $\mathrm{Pb}^{2+}$, and the $\mathrm{x}$ site anion is $\mathrm{I}^{-}$in $\mathrm{CH}_{3} \mathrm{NH}_{3} \mathrm{PbI}_{3}\left(\mathrm{MAPbI}_{3}\right)$. $\mathrm{MAPbI}_{3}$ has attracted attention as a light-absorbing resource for next-generation solar cells ${ }^{1-5}$ due to its high absorption coefficient ${ }^{6}$, tunable bandgap ${ }^{7}$, long carrier diffusion length $^{8-11}$, and low-cost ${ }^{12,13}$. Studies on sequential deposition ${ }^{14,15}$, solution processes ${ }^{16-18}$, vapor deposition ${ }^{19}$, and vapor-assisted solution processes ${ }^{20}$ have been developed to obtain high-quality $\mathrm{MAPbI}_{3}$. However, unbalanced carrier-mobility switches the direction and speed of the voltage sweep and leads to current density-voltage $(\mathrm{J}-\mathrm{V})$ hysteresis in mesoscopic structures ${ }^{21,22}$. To overcome this problem, charge transport material and charge transport layer/ $\mathrm{MAPbI}_{3}$ interface studies ${ }^{23-26}$ and perovskite material studies ${ }^{27,28}$ have been conducted . In addition to forming a planar structure that eliminates the mesoporous (MP) layer which causes the J-V hysteresis problem, an inverted structure that changes the direction for reaching the electrodes of electrons and holes were studied, in which the efficiency of the perovskite solar cell (PSC) realized values higher than $23 \%{ }^{29-34}$. To date, experiments have most often been conducted in laboratory conditions in the absence of moisture and oxygen such as inert atmosphere. These processes and systems are expensive to perform because they relate to commercialization conditions that demand high stability with the additive-free hole transporter materials ${ }^{35,36}$, durability, and excellent performance, as well as large-scale, low cost, and ambient air manufacturing. To meet the above conditions, large-scale deposition techniques ${ }^{37-40}$ and an encapsulation process ${ }^{41-44}$ were studied. Research regarding the fabricating of PSCs in ambient air conditions is currently at the foundational stage. One important aspect of ambient air conditions processes is the formation of high-quality films of oxygen-sensitive $\mathrm{MAPbI}_{3}$ materials ${ }^{45}$. Recent studies considered the positive and negative aspects of the effect of moisture on $\mathrm{MAPbI}_{3}$ using different approaches. For example, a small amount of water was added to the $\mathrm{MAPbI}_{3}$ precursor solvent during the deposition process to create a compact film ${ }^{46}$. It is important to note that the $\mathrm{MAPbI}_{3}$ layer

${ }^{1}$ Department of Chemistry, Sungkyunkwan University, Suwon 440-746, Korea. ${ }^{2}$ Institute of Basic Science, Sungkyunkwan University, Suwon 440-746, Korea. ${ }^{\circledR}$ email: jhboo@skku.edu 
had been protected from moisture to help transfer the carrier using an interlayer at the interface between the $\mathrm{MAPbI}_{3}$ and the transport layers.

Non-radiative recombination caused through defect formation at the transport layer/MAPbI ${ }_{3}$ interface, has been identified as a cause of efficiency loss in the $\mathrm{PSCs}^{47}$. The causes of $\mathrm{MAPbI}_{3}$ defects include temperature, bias voltage, ultraviolet-A rays (UV-A), and moisture. The exact cause of these defects must be identified according to research conducted to date; accordingly, the defect site was shown as having been generated by metal (lead(II), $\mathrm{Pb}^{2+}$ ) and/or halide $\left(\mathrm{I}^{-}\right)$ions remaining at the transport layer/MAPbI layer interface ${ }^{48}$. Non-radiative recombination through a defect formed at the transport layer/MAPbI $\mathrm{M}_{3}$ layer interface can reduce optical properties and cell parameters, and can lead to $\mathrm{J}-\mathrm{V}$ hysteresis and the long-term stability of $\mathrm{J}-\mathrm{V}$ characteristics ${ }^{49}$. To maintain cell performance and stability, it is essential to reduce, the loss of non-radiative recombination at the transport layer/ $\mathrm{MAPbI}_{3}$ layer interface. Recent studies have reported that non-radiative recombination in the device using the passivation layer at the interface was able to improve device stability ${ }^{50} . \mathrm{Pb}^{2+}$, which remains as a junction at the transport layer/ $\mathrm{MAPbI}_{3}$ interface, is being studied to reduce defects using electron donor materials or Lewis-base materials. Representative materials such as polymers PVP ${ }^{51}$ and PCDTBT ${ }^{52}$ polymers, and devices have been found to increase carrier lifetime and voltage when passivated with Lewis basic thiophene and pyridine. Other organic passivation materials with fullerenes include $\mathrm{PCBM}^{53}$, graphene ${ }^{54}$ and $\mathrm{PMMA}^{55}$. Beside the chemical passivation, a physical passivation can also improve the stability of $\mathrm{PSCs}^{56,57}$.

$\mathrm{MAPbI}_{3}$ materials comprise organic and inorganic hybrids. MP- TiO ${ }_{2} \mathrm{PSCs}$ have decreased stability under UV-A light conditions due to the changes in $\mathrm{MP}^{-\mathrm{TiO}_{2}}$ electron transport layers (ETL) widely used in highperformance $\mathrm{PSCs}^{58}$. When the $\mathrm{MP}^{\mathrm{T}} \mathrm{TiO}_{2}$ layer is exposed to UV-A light, the photogenerated holes react with the oxygen that is absorbed in the surface oxygen vacancies this causes to deeply re-collect and gives rise to charge recombination. In the present study, an ultra-thin polyaniline passivation layer (PPL) was inserted into the ETL/ $\mathrm{MAPbI}_{3}$ interface to manufacture a passivated PSC. The PPL trapped $\mathrm{Pb}^{2+}$ ions and absorbed light in the UV-A region improved the performance of the PSC, and reduced the interface carrier recombination. In addition, the P-type doping effect of an N-type ETL using a polyaniline (PANI) material caused a voltage increase through the enhancement of the overall Fermi-energy level in the device. A passivated PSC with $15.1 \%$ efficiency and an outstanding Voc of approximately $0.99 \mathrm{~V}$ was achieved. This study concludes that PPL can suppress the charge state of $\mathrm{Pb}^{2+}$ defect at the $\mathrm{ETL} / \mathrm{MAPbI}_{3}$ interface, thereby effectively reducing non-radiative recombination.

\section{Results and discussion}

PANI polymers are classified into leucoemeraldine (fully reduced state), emeraldine (intermediate state), and nigraniline (fully oxidized state) according to the degree of oxidation and reduction. In the process of preparing PANI solution, PANI of leucoemeraldine state seems to have been oxidized and changed to emeraldine state. Therefore, PPL can absorb light from UV-A and visible light in a specific region. This was because $\mathrm{MAPbI}_{3} \mathrm{was}$ decomposed by light in the UV-A region. Emeraldine PANI absorbed light in the UV-A region, which protected the $\mathrm{MAPbI}_{3}$ from being decomposed by UV-A light. PANI is classified as an intractable polymer, particularly when in the form of a conductive polymer. There are three ways in which to heighten the molecular weight of a PANI solution state (1) acid, (2) blend-solvent, and (3) an organic solvent. In this study, the ETL comprised $\mathrm{TiO}_{2}$, which was dissolved by an acid via the reaction shown in Eq. (1).

$$
\mathrm{TiO}_{2}+4 \mathrm{HCl} \rightarrow \mathrm{TiCl}_{4}+2 \mathrm{H}_{2} \mathrm{O}
$$

An acid could not, however, be used as a solvent, accordingly, this study focused on organic solvents. In existing research, it was shown to dissolve well in polar solvents with strong hydrogen-bonding groups, such as cresols, phenols, trifluoroethanol, DMSO, and DMF. However, contrary to expectations, it still did not dissolve. The present study attempted to dissolve in ethanol and 2-propanol, but the same outcome was obtained. PANI powder appeared to have been dissolved in DMSO and DMF, however, it gradually begins to precipitate over time. Conversely, in the NMP solvent, the phenomenon mentioned above was not observed. A $1 \%$ organic solvent was able to dissolve PANI. Figure 1 shows the graphical images of PANI powder dissolved in various organic solvents before being coated onto a glass substrate. When PANI dissolved in NMP was coated onto a glass substrate, the entire glass substrate became a light-blue color. Contrastingly, no significant difference was observed on the glass substrate when using other solvents. The transmittance was measured to confirm the advantages of the PPL while maintaining the high transparency imbued by the glass electrode.

Figure 2a shows the transmittance of the PANI/glass substrate. Unlike that of the glass substrate, the transmittance curve of the PANI/glass substrate has changed. In the case of a glass substrate, the transmittance was slightly below $90 \%$ in the visible light region, when the PPL was deposited onto the glass substrate, the transmittance was reduced by approximately $1-2 \%$. The PANI/glass sample showed lower transmittance in the UV-A range compared with the glass substrate. The PPL absorbed light within the UV-A region, therefore the transmittance of the PANI/glass sample in the range of 300-350 nm was significantly lower than for the glass sample. However, PPL absorbed in the visible region as well, which is the absorption region of perovskite. The PPL absorbed light within the UV-A region, therefore, the transmittance of the PANI/glass sample in the range of 300-350 nm was significantly lower than for the glass sample. The current density (Jsc) of the PSC may have decreased when the PPL was inserted into the ETL/MAPbI ${ }_{3}$ interfaces. However, the decrease in light amount of UV-A region improved the stability of the PSC. The XRD measurements for the phase identification of the $\mathrm{MAPbI}_{3}$ films on the $\mathrm{CP}-\mathrm{TiO}_{2} / \mathrm{FTO}$ substrate, with and without PANI, are shown in Fig. 2b. The diffraction peaks of $\mathrm{PbI}_{2}$ that appeared at $12.6^{\circ}, 34.3^{\circ}, 39.5^{\circ}$, and $52.3^{\circ}$ were assigned to the (001), (012), (003), and (004) lattice planes. The diffraction patterns at $14.2^{\circ}, 20.0^{\circ}, 23.6^{\circ}, 24.6^{\circ}, 28.5^{\circ}, 31.9^{\circ}, 35.0^{\circ}, 40.6^{\circ}$, and $43.2^{\circ}$ were assigned to the $(110)$, (200), (211), (202), (220), (310), (312), (224), and (314) lattice planes of the $\mathrm{MAPbI}_{3}$. The $\mathrm{MAPbI}_{3}$ crystals were formed via the reaction shown in Eq. (2). 


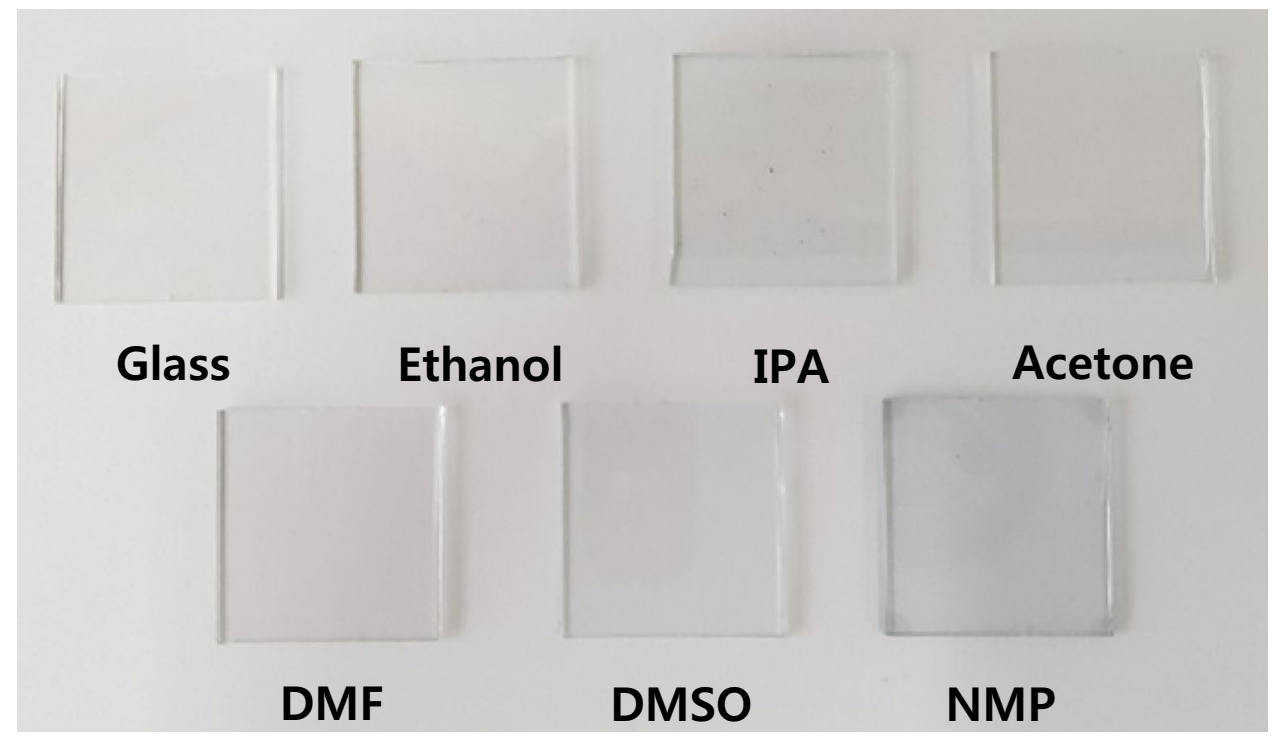

Figure 1. Graphical images of the PANI passivation layer (PPL), based on the solvent used.

(a)

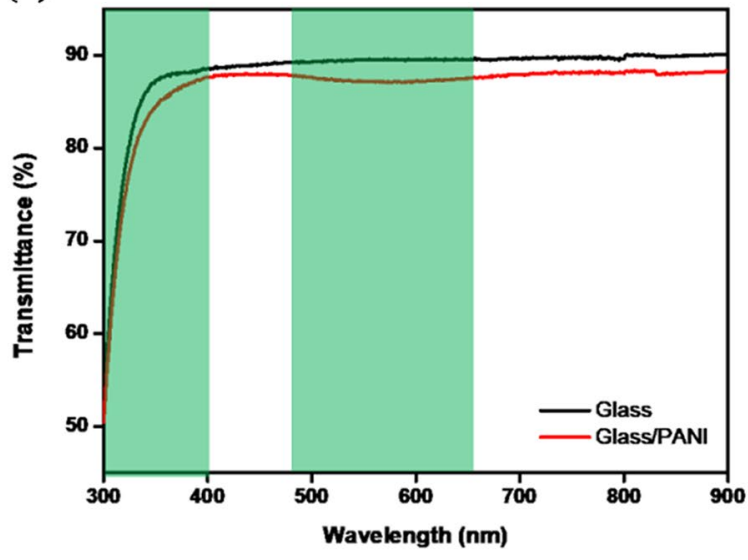

(b)

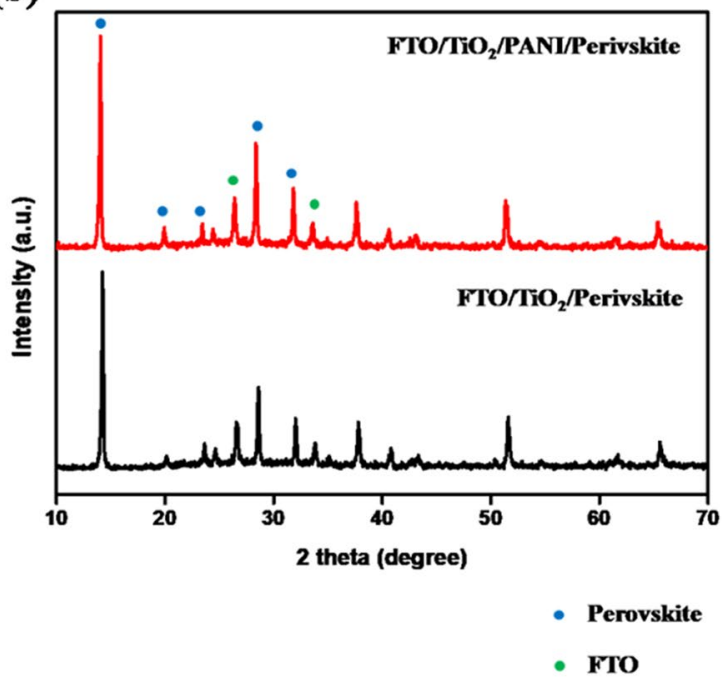

Figure 2. (a) The UV-Vis transmittance of glass with the PPL. (b) X-ray diffraction of the perovskite layer with/without PPL.

$$
\mathrm{PbI}_{2}+\mathrm{CH}_{3} \mathrm{NH}_{3} \mathrm{I} \rightarrow \mathrm{CH}_{3} \mathrm{NH}_{3} \mathrm{PbI}_{3}
$$

If the amount of $\mathrm{MAPbI}_{3}$ precursor was not sufficient for enabling a reaction, the PPL would adversely affects the formation of $\mathrm{MAPbI}_{3}$, and unreacted $\mathrm{PbI}_{2}$ would remain in the $\mathrm{MAPbI}_{3}$ film, this would present as an impurity in the $\mathrm{XRD}$ results. The $\mathrm{MAPbI}_{3}$ layer was deposited onto the $\mathrm{CP}-\mathrm{TiO}_{2} /$ glass sample and almost $\mathrm{PbI}_{2}$ impurities were not identified from the XRD results. The $\mathrm{PANI} / \mathrm{CP}-\mathrm{TiO}_{2} /$ glass sample indicated the same results. This meant that the PPL did not affect the reaction in which the $\mathrm{MAPbI}_{3}$ crystallized.

Figure 3a shows the SEM cross-section image of the PPL. The thickness of the PPL is $65 \mathrm{~nm}$ and changes according to the number of coatings, as is summarized in Fig. $3 \mathrm{~b}$. As the number of coatings increased, the thickness of the PPL increased by $35 \mathrm{~nm}$. After the number of coating was four times, a thickness of $170 \mathrm{~nm}$ was obtained. If the PPL is too thick, the transmittance will be lowered and the advantages of the glass electrode will be undermined. Figure $3 \mathrm{c}$ shows the transmittance according to the thickness of the PPL. As the number of coatings increased, the transmittance gradually reduced by $2 \%$ as indicated by the formation of the blue color on the PANI material. 
(a)

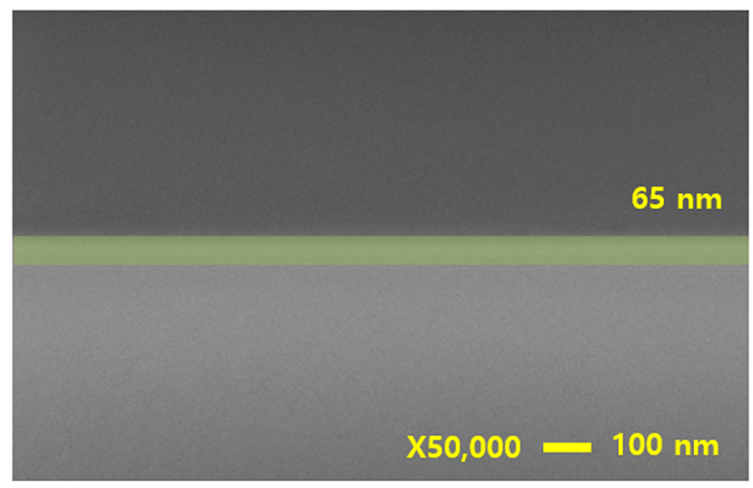

(c)

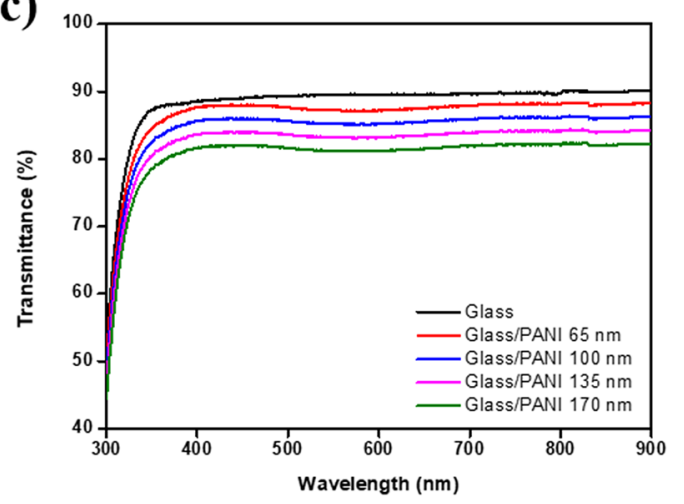

(b)

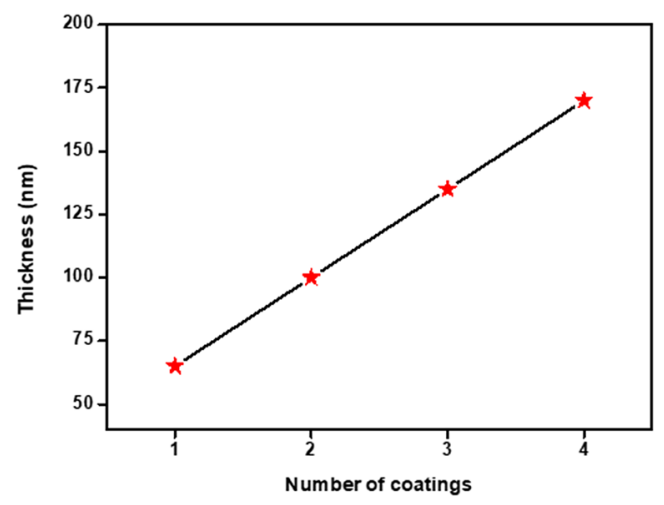

Figure 3. (a) The SEM image of the PPL (cross section image). (b) The thickness of the PPL and (c) the transmittance of the PPL according to its thickness.

Figure 4a shows the details of the performance parameters of the PSCs as summarized in Table 1. One important effect of the PPL was that it increased the Voc. The voltage was improved due to the increase of the overall Fermi-energy level due to the P-type PPL doping effect of the N-type ETL. The Voc of the base sample was $0.96 \mathrm{~V}$, which increased to $0.99 \mathrm{~V}$ with a $65 \mathrm{~nm}$-PPL sample, a relative increase of $0.03 \mathrm{~V}$. In addition, the Jsc of the $65 \mathrm{~nm}$-PPL sample was increased to be $5.76 \mathrm{~mA} / \mathrm{cm}^{2}$ compared with the base sample. Concurrently, the fill factor (FF) of the passivated PSC was minimally enhanced (by $2 \%$ ), which this study ascribed to a decreased series resistance. Accordingly, a PSC with $65 \mathrm{~nm}$-PPL sample was obtained at $15.1 \%$ of power conversion efficiency (PCE). When the PPL became thicker, the Jsc was slightly reduced due to a transmittance reduction in the visible region. As a result, the PCE gradually decreased the thickness of the PPL exceeds $65 \mathrm{~nm}$-PPL. Figure $4 \mathrm{~b}$ confirms the effect of the PPL on the non-radiative recombination of the base and $65 \mathrm{~nm}$-PPL samples. Figure $4 \mathrm{~b}$ shows the efficiency variation was measured for one month with the light blocked. The base sample lost $24 \%$ efficiency over the month, while the $65 \mathrm{~nm}$-PPL sample's efficiency was reduced by only $16 \%$. The $\mathrm{Pb}^{2+}$ ions of the oxidation-decomposed $\mathrm{MAPbI}_{3}$ moved to the ETL/MAPbI interfaces, which affected carrier lifetime and mobility, and led to hysteresis. As a result, more $\mathrm{Pb}^{2+}$ ions were produced by oxidation over time, and the performance of the PSC decreased more rapidly. The PANI polymer material had a large number of lone pair electrons, which confined $\mathrm{Pb}^{2+}$ ions. The efficiency reduction amount of the $65 \mathrm{~nm}$-PPL sample was smaller compared with the base sample. Figure $4 \mathrm{c}$ shows the minimal hysteresis of the $65 \mathrm{~nm}$-PPL sample with respect to the voltage sweep.

Figure 5a shows the solar cell circuit. To obtain a high-efficiency in the solar cell, the series resistance should be low and the shunt resistance should be high. If the series resistance is high, electrons cannot move smoothly along the circuit, and if the shunt resistance is low, leakage current will occurs, resulting in PSCs with poor efficiency and stability. These changes also affected the fill factor (FF) curve (see Fig. 5b). If the series resistance was high or the shunt resistance was low, the FF and the maximum output of the PSC would decrease. Based on the presence and the thickness of the PPL, the series and shunt resistances are shown in the Fig. $5 \mathrm{c}$,d, and the values are summarized in Table 2. The series resistance value of the base sample was $16.70 \Omega$ and the series resistance value decreased to $6.12 \Omega$ when the $65 \mathrm{~nm}$-PPL was inserted. As the PPL became thicker, the series resistance increased. The $170 \mathrm{~nm}$-PANI sample obtained a value of $17.12 \Omega$, which was higher compared with the base sample. The shunt resistance value of the base sample was $5157.43 \Omega$ and the was enhanced to $9122.47 \Omega$ when the $65 \mathrm{~nm}$-PPL was inserted. As the thickness of the PPL increased, the shunt resistance gradually decreased. The $170 \mathrm{~nm}$ PPL sample obtained a value of $4952.32 \Omega$, which was lower compared with the base sample. For the $65 \mathrm{~nm}$-PPL sample, the ideal resistance value and the stability of the PSC were improved. The PL and impedance spectroscopy measurements were conducted to confirm the cause of cell parameter changes, based on the presence or absence of the PPL. 
(a)

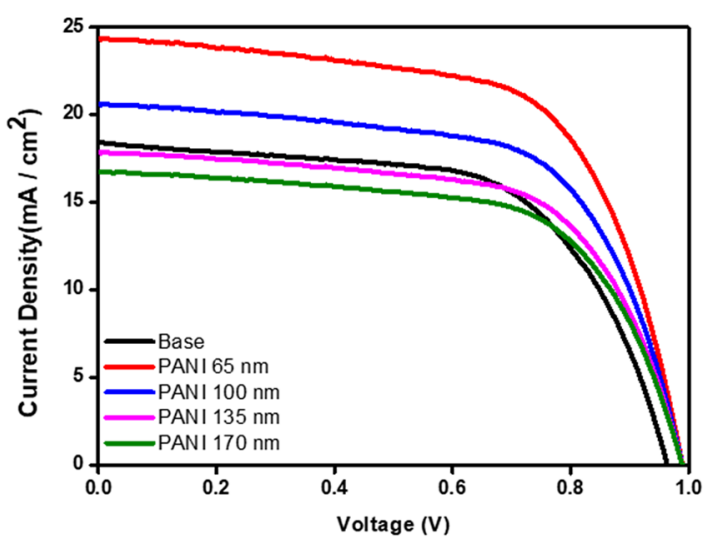

(c)

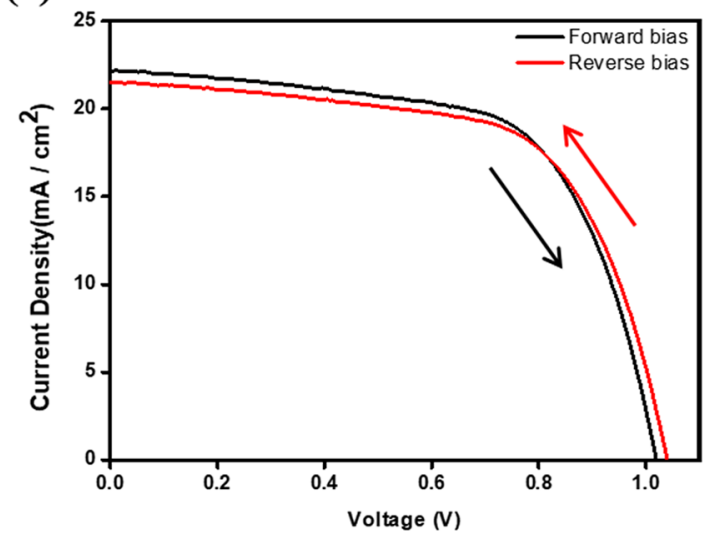

(b)

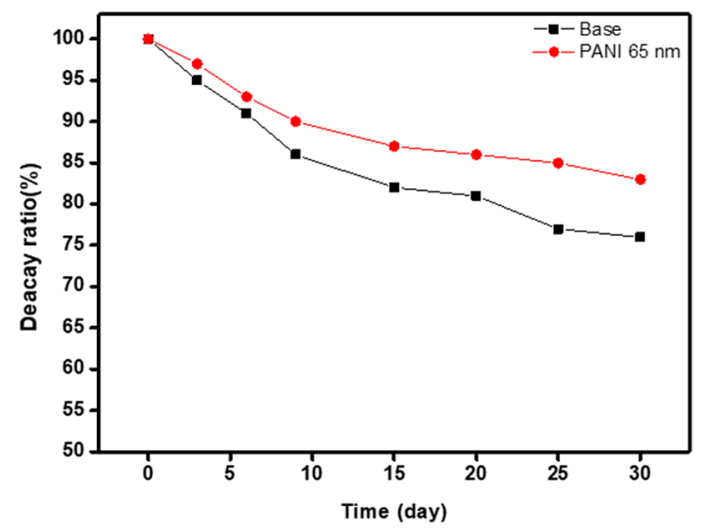

Figure 4. (a) The J-V curve and (b) the time-dependent evolution of efficiency (c) the J-V curve hysteresis of the perovskite solar cell with the PPL.

\begin{tabular}{|l|l|l|l|l|}
\hline Sample & Jsc $\left(\mathbf{m A} / \mathbf{c m}^{2}\right)$ & Voc $($ V) & FF (\%) \\
\hline Base & 17.95 & 0.96 & 62.1 & PCE (\%) \\
\hline $65 \mathrm{~nm}$ & 23.71 & 0.99 & 64.2 & 10.7 \\
\hline $100 \mathrm{~nm}$ & 20.10 & 0.98 & 64.1 & 63.2 \\
\hline $135 \mathrm{~nm}$ & 13.40 & 0.98 & 12.7 & 11.0 \\
\hline $170 \mathrm{~nm}$ & 16.30 & 0.98 & 64.4 & \\
\hline
\end{tabular}

Table 1. Photovoltaic performance parameters summarized J-V measurements with different PPL thickness.

Figure 6a shows the PL curve. The area of the PL spectrum refers to the carrier recombination rate or carrier mobility. The results of the PL were affected by both the degree of exciton generation and the mobility of the carrier. For the $65 \mathrm{~nm}$-PPL sample, the PL area was very small compared with the base sample. As the carrier lifetime increased, more electrons could reach the electrode, thereby increasing the current. Conversely, if the PPL was too thick, the recombination rate of the carrier was enhanced and the transmittance decreased. For this reason, the Jsc was reduced. The EIS measured the resistance at the interface (see Fig. 6b). The EIS included two resistors and capacitors (RC) arcs, one of which was related to the contact resistance of the interfaces at a high frequency and the other was attributed to the recombination resistance and chemical capacitance of the device at low a frequency. The EIS reflected the charge transfer resistance and recombination at the ETL/MAPbI interfaces and $\mathrm{MAPbI}_{3} /$ counter electrode in the PSC field. The $65 \mathrm{~nm}$-PPL sample exhibited smaller series resistance and larger recombination resistance compared with the base sample. This indicates that the carrier's transport ability had been improved and the recombination rate of the carrier had been reduced for the $65 \mathrm{~nm}$ PPL sample. Conversely, the $170 \mathrm{~nm}$-PPL sample exhibited larger series resistance and smaller recombination resistance compared to other sample. This result implies that the carrier's transport ability had been reduced and the recombination rate of carrier was increased for the $170 \mathrm{~nm}$-PPL sample. This means that for the $170 \mathrm{~nm}$ PPL sample, the carrier's transport ability had been reduced when the carrier recombination rate was increased. 
(a)

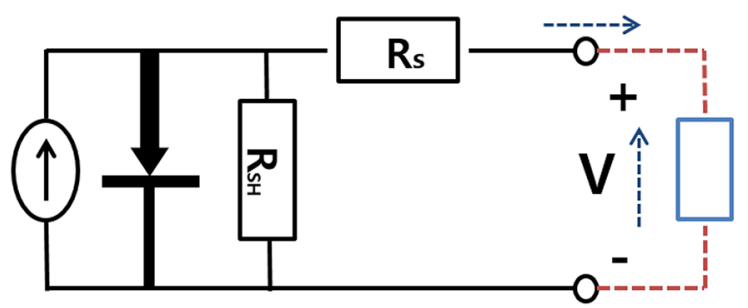

(c)

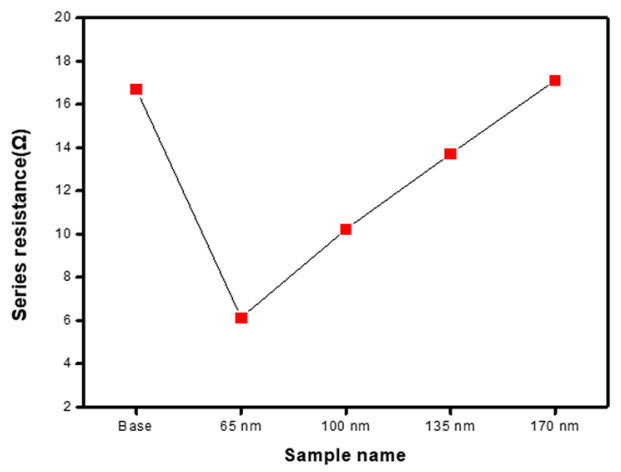

(b)

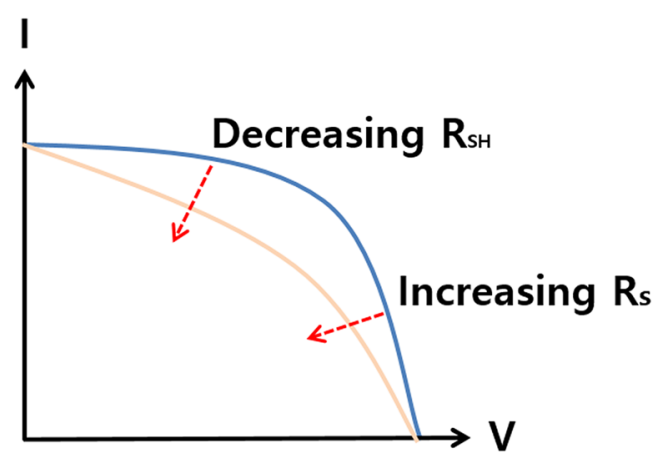

(d)

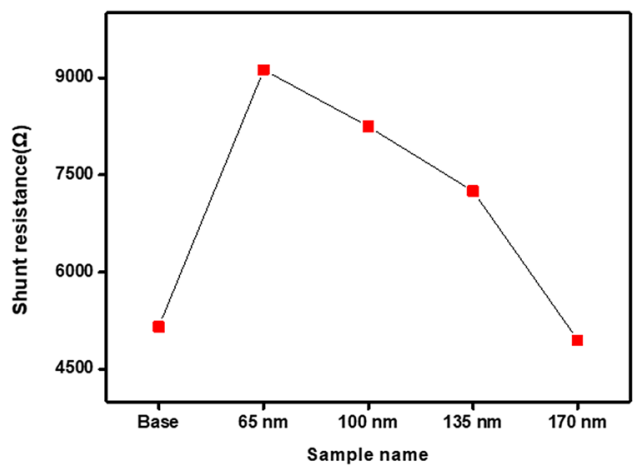

Figure 5. (a) The circuit and (b) the fill factor curve of the solar cell and (c) the series resistance and (d) the shunt resistance of the perovskite solar cell with PPL.

\begin{tabular}{|l|l|l|l|r|r|}
\hline & Base & $\mathbf{6 5} \mathbf{n m}$ & $\mathbf{1 0 0} \mathbf{n m}$ & $\mathbf{1 3 5} \mathbf{n m}$ & $\mathbf{1 7 0} \mathbf{n m}$ \\
\hline $\mathrm{R}_{\mathrm{s}}(\Omega)$ & 16.70 & 6.12 & 10.23 & 13.71 & 17.12 \\
\hline $\mathrm{R}_{\text {sh }}(\Omega)$ & 5157.43 & 9122.47 & 8247.47 & 7250.49 & 4952.32 \\
\hline
\end{tabular}

Table 2. Comparison of series and shunt resistances of perovskite solar cell with different PPL thickness.

(a)

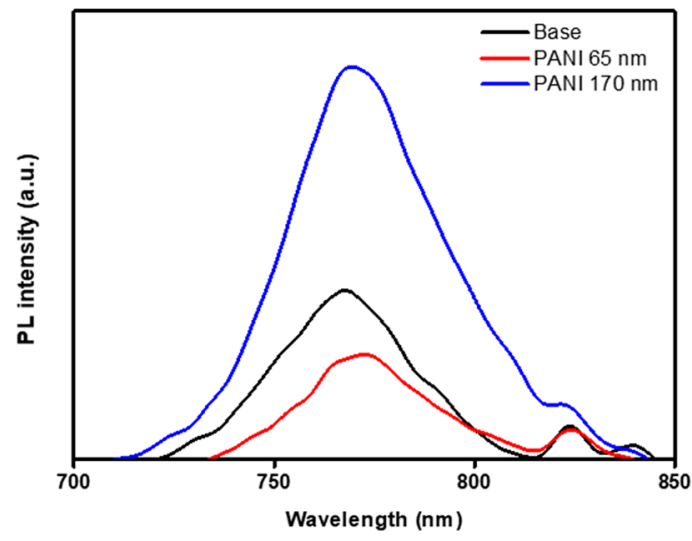

(b)

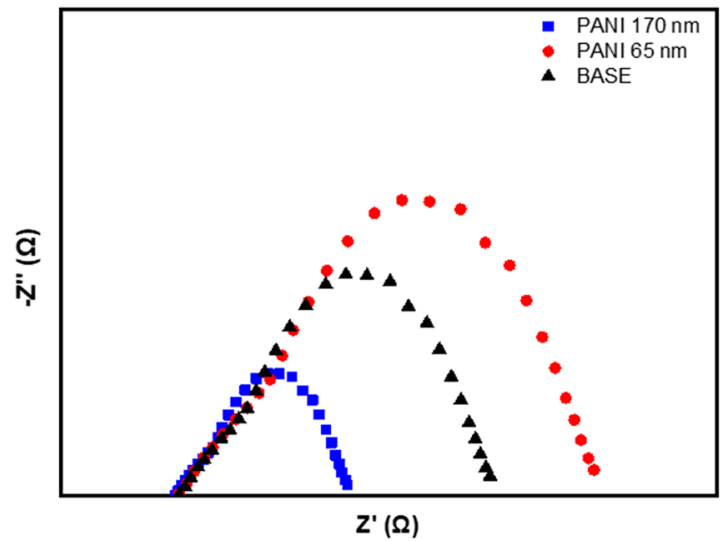

Figure 6. (a) The PL intensity and (b) the impedance of the perovskite solar cell with the PPL. 
(a)

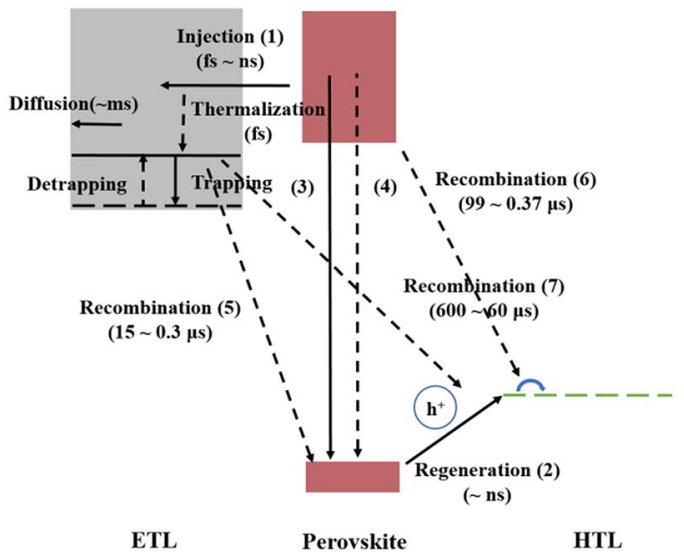

(b)

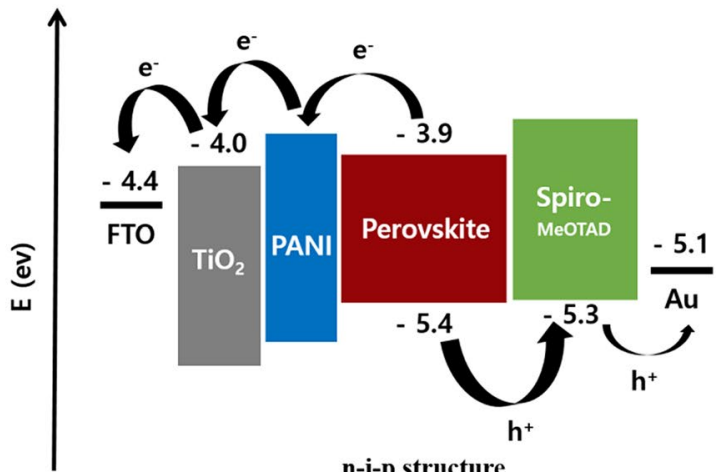

n-i-p structure

Scheme 1. (a) Schematic diagram of carrier transfer processes in perovskite solar cells and (b) Energy band diagram of perovskite solar cells with PPL.

\begin{tabular}{|c|c|c|c|c|}
\hline YYYY.MM & PCE (\%) & Cell area $\left(\mathrm{cm}^{2}\right)$ & Device structure & References \\
\hline 2015.04 & 10.1 & 0.24 & $\begin{array}{l}\text { ITO/PEDOT:PSS/Perovskite/ } \\
\text { PCBM/BCP/Ag }\end{array}$ & 59 \\
\hline 2015.09 & 18.0 & & $\begin{array}{l}\text { ITO/PEDOT:PSS/Perovskite/ } \\
\text { PCBM/Ca/Al }\end{array}$ & 29 \\
\hline 2015.09 & 9.4 & 0.092 & $\begin{array}{l}\mathrm{FTO} / \mathrm{TiO}_{2} / \mathrm{Al}_{2} \mathrm{O}_{3}+\text { Perovskite/ } \\
\text { SWCNTs/PMMA/Ag }\end{array}$ & 60 \\
\hline 2016.10 & 12.0 & & $\begin{array}{l}\text { ITO/PEDOT:PSS/Perovskite/ } \\
\text { PCBM/C } 60 \text { /BCP/Ag }\end{array}$ & 61 \\
\hline 2017.01 & 18.1 & 0.1 & $\begin{array}{l}\text { ITO/Poly-TPD/Perovskite/C } 60 / \\
\text { BCP/Ag }\end{array}$ & 63 \\
\hline 2017.02 & 15.6 & 0.126 & $\begin{array}{l}\mathrm{FTO} / \mathrm{TiO}_{2} / \text { Perovskite/ZrO }{ }_{2} / \\
\text { Carbon }\end{array}$ & 64 \\
\hline 2018.01 & 18.7 & 4.85 & $\begin{array}{l}\text { ITO/PEDOT:PSS/Perovskite/C } 60 / \\
\text { BCP/Ag }\end{array}$ & 65 \\
\hline
\end{tabular}

Table 3. Efficiency comparison of the results of other group reported in ambient air process perovskite solar cell.

Scheme 1a summarizes the carrier transfer processes and Scheme $1 \mathrm{~b}$ shows energy band diagram structure of the PSCs. The effect of the voltage enhancement via improvement of Fermi-energy level in the device (through the doping of a P-type material to an N-type ETL) was confirmed. If the thickness of the PANI layer is thin, separated electrons from the $\mathrm{MAPbI}_{3}$ are well injected into the(conduction band) ETL ((1): $\left(\mathrm{e}^{-}\right.$(electron)- $\mathrm{h}^{+}$ (hole)) $\left.\mathrm{MAPbI}_{3} \rightarrow \mathrm{e}_{\mathrm{cb} \text { (conduction band) }}{ }^{-}(\mathrm{ETL})+\mathrm{h}^{+}\left(\mathrm{MAPbI}_{3}\right)\right)$ and the carrier recombination rate according to back charge transfer $\left((5): \mathrm{e}_{\mathrm{cb}}{ }^{-}(\mathrm{ETL})+\mathrm{h}^{+}\left(\mathrm{MAPbI}_{3}\right) \rightarrow\right.$ recombination) is reduced due to the HOMO-energy level of the relatively high ETL. If the thickness of PANI layer becomes too thick, electrons cannot pass through the ETL and exciton annihilationn $\left((3):\left(\mathrm{e}^{-}-\mathrm{h}^{+}\right)\right.$perovskite $\rightarrow \mathrm{PL}$ and $(4):\left(\mathrm{e}^{-}-\mathrm{h}^{+}\right) \mathrm{MAPbI}_{3} \rightarrow$ non-radiative recombination) and back charge transfer $\left((6): \mathrm{h}^{+}(\mathrm{HTL})+\mathrm{e}^{-}\left(\mathrm{MAPbI}_{3}\right)\right)$ occurs at the PPL/MAPbI ${ }_{3}$ interface. The recombination resistance and carrier lifetime were improved through the insertion of a conducting PANI polymer, thereby improving the FF and Jsc. These effects resulted in improved PSC stability and efficiency. The $\mathrm{Pb}^{2+}$ ions, which represent an impurity generated by oxidation over time due to non-radiative recombination, was trapped in the PPL, thereby providing stability over time.

Table 3 summarizes the PSCs manufacturing in relation to atmospheric conditions and moisture. The research on manufacturing PSCs under atmospheric conditions in relation to oxygen is a very important in the context of commercialization, not only in terms of stability but also in relation to manufacturing costs. Existing research has attempted to add a hydrophilic material to a precursor solution or a coating process to resist oxygen effects. In addition, various studies have been conducted to improve the stability and efficiency while lowering the manufacturing costs of all manufacturing processes performed in the atmospheric conditions. The present research shows that all the manufacturing processes were conducted as part of the atmospheric process. Furthermore, it 
indicates the improvement of the stability and efficiency of the PPL, as well as its high level of performance when comparing the efficiency/cell area with other research teams.

\section{Conclusions}

This study demonstrated a passivated $\mathrm{MAPbI}_{3}$ structure for suppressing defects at the interface of an ETL/ $\mathrm{MAPbI}_{3}$ using a PPL. The PPL absorbed UV-A to prevent damage to the MAPbI layer and suppressed nonradiative recombination between the $\mathrm{MAPbI}_{3}$ and $\mathrm{ETL}$ interface. Increasing the stability and performance of the PSC represents a significant advantage, that is, the PPL's reduced carrier recombination rate. As a result, a Voc of $0.99 \mathrm{~V}$ was obtained, and a conversion efficiency of $15.1 \%$ was realized for the PSC. The PPL is generally applicable to other organic and organic-inorganic solar cells for improving their efficiency and stability. To improve PSC's stability, a variety of donor-acceptor materials can be used with PANI to suppress non-radiative recombination.

\section{Methods}

Preparation of materials. The synthesis of $\mathrm{CH}_{3} \mathrm{NH}_{3} \mathrm{I}$ powder: A methylamine $(27.8 \mathrm{ml}, 40 \mathrm{wt} \%$ in methanol, TCI) and hydroiodic acid $\left(30 \mathrm{ml}, 57 \mathrm{wt} \%\right.$ in water, Sigma-Aldrich) mixture solution were stirred at $0{ }^{\circ} \mathrm{C}$ for $2 \mathrm{~h}$. To remove the solvent of the synthesized $\mathrm{CH}_{3} \mathrm{NH}_{3} \mathrm{I}$ powder, the mixture was rotary evaporated at $50^{\circ} \mathrm{C}$ for $1 \mathrm{~h}$. The $\mathrm{CH}_{3} \mathrm{NH}_{3} \mathrm{I}$ powder was washed with diethyl ether and dried in an oven at $60^{\circ} \mathrm{C}$ for $24 \mathrm{~h}$.

Preparation of PANI solution: $0.1 \mathrm{mg}$ of PANI (emeraldine base, Sigma-Aldrich) is dissolved in $1 \mathrm{ml}$ of 1-Methyl-2-pyrrolidinone (NMP, 99.5\%, Sigma-Aldrich), followed by stirring at $70^{\circ} \mathrm{C}$ for $24 \mathrm{~h}$.

Fabrication of the PSCs. The fluorine doped tin oxide (FTO) substrate was etched with $\mathrm{Zn}$ dust and $2 \mathrm{M}$ hydrochloric acid and cleaned with acetone and 2-propanol for $10 \mathrm{~min}$ respectively. The FTO substrate was dried with nitrogen and exposed to oxygen plasma treatment. To creat the $\mathrm{TiO}_{2}$ compact layer $\left(\mathrm{CP}-\mathrm{TiO}{ }_{2}\right)$, $0.10 \mathrm{M}$ titanium diisopropoxide bis (acetylacetonate) (Sigma-Aldrich, $75 \mathrm{wt} \%$, in IPA, Signa-Aldrich) solution was deposited on the FTO substrate and annealed at $450{ }^{\circ} \mathrm{C}$ for $30 \mathrm{~min}$. The PANI solution was then coated onto the $\mathrm{CP}-\mathrm{TiO}_{2}$ layer. A mixture solution of $1.0 \mathrm{M} \mathrm{PbI}_{2}\left(1.0 \mathrm{M}\right.$, Sigma-Aldrich) and $1.0 \mathrm{M} \mathrm{CH}_{3} \mathrm{NH}_{3} \mathrm{I}$ in $N, N-$ Dimethylformamide (DMF), and dimethylsulfoxide (DMSO) at a ratio of 4:1 (v:v), was coated on the PPL and dried at $100{ }^{\circ} \mathrm{C}$ for $10 \mathrm{~min}$. A Spiro-MeOTAD containing [28.8 $\mu \mathrm{L}$ of Spiro-MeOTAD (Lumtec) $(72.3 \mathrm{mg} / \mathrm{mL}$ in chlorobenzene), 4-tert-butylpyridine (Sigma-Aldrich, 96\% The TSFI stock solution (Sigma-Aldrich, 99.8\%) was stirred for $24 \mathrm{~h}$ )] was coated on the $\mathrm{MAPbI}_{3}$ layer. A gold electrode was created using thermal evaporation equipment.

Characterization. Film X-ray diffraction (XRD) (Bruker D8 Advance system) measurement was performed using $\mathrm{Cu} \mathrm{Ka}$ radiation $(\lambda=1.5416 \AA)$ with a $40 \mathrm{kV}$ beam voltage and a $30 \mathrm{~mA}$ beam current. Scanning electron microscopy (SEM) was performed using a JEOL, JSM-7100F instrument. The transmittance and absorbance (ABS) characteristics were recorded using a UV-Vis-near-infrared (NIR) spectrometer (UV-3600, Shimadzu) in the wavelength range of 300-900 $\mathrm{nm}$ with an integrated sphere attachment. The photoluminescence (PL) was measured by using a FluroMate (FS-2) fluorescence Sperctrometer. The photovoltaic performance (SUN 2000) was achieved using a xenon lamp under an AM 1.5 filter at $100 \mathrm{~mW} / \mathrm{cm}^{2}$ illuminations in open circuit conditions. The resistances of the PSCs were obtained using the Iviumsoft program. Electrochemical impedance spectroscopy (EIS) was performed in a frequency range from $1 \mathrm{MHz}$ to $100 \mathrm{mHz}$ using a SUN 2000 Instrument under an alternating current voltage with a perturbation amplitude of $10 \mathrm{mV}$ was applied in the EIS measurements.

Received: 10 September 2021; Accepted: 17 December 2021

Published online: 13 January 2022

\section{References}

1. Kojima, A., Teshima, K., Shirai, Y. \& Miyasaka, T. Organometal halide perovskites as visible-light sensitizers for photovoltaic cells. J. Am. Chem. Soc. 131, 6050-6051. https://doi.org/10.1021/ja809598r (2009).

2. Kim, H. S. et al. Lead iodide perovskite sensitized all-solid-state submicron thin film mesoscopic solar cell with efficiency exceeding 9\%. Sci. Rep. 591, 1-7. https://doi.org/10.1038/srep00591 (2012).

3. Kagan, C. R., Mitzi, D. B. \& Dimitrakopoulos, C. D. Organic-inorganic hybrid materials as semiconducting channels in thin-film field-effect transistors. Science 286, 945-947. https://doi.org/10.1126/science.286.5441.945 (1999).

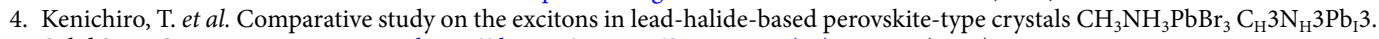
Solid State Commun. 127, 619-623. https://doi.org/10.1016/S0038-1098(03)00566-0 (2003).

5. Heo, J. H. et al. Efficient inorganic-organic hybrid heterojunction solar cells containing perovskite compound and polymeric hole conductors. Nat. Photonics 7, 486-491. https://doi.org/10.1038/nphoton.2013.80 (2013).

6. Michael, M. L., Joël, T., Tsutomu, M., Takurou, N. M. \& Henry, J. S. Efficient hybrid solar cells based on meso-superstructured organometal halide perovskites. Science 338, 643-647. https://doi.org/10.1126/science.1228604 (2012).

7. Jun, H. N., Sang, H. I., Jin, H. H., Tarak, N. M. \& Sang, I. S. Chemical management for colorful, efficient, and stable inorganicorganic hybrid nanostructured solar cells. Nano Lett. 13, 1764-1769. https://doi.org/10.1021/nl400349b (2013).

8. Samuel, D. S. et al. Electron-hole diffusion lengths exceeding 1 micrometer in an organometal trihalide perovskite absorber. Science 342, 341-344. https://doi.org/10.1126/science.1243982 (2013).

9. Eran, E. et al. Elucidating the charge carrier separation and working mechanism of $\mathrm{CH}_{3} \mathrm{NH}_{3} \mathrm{PbI}_{3 \_\mathrm{x}} \mathrm{Cl}_{\mathrm{x}}$ perovskite solar cells. Nat. Commun. 5, 1-8. https://doi.org/10.1038/ncomms4461 (2014).

10. Christian, W., Giles, E. E., Michael, B. J., Henry, J. S. \& Laura, M. High charge carrier mobilities and lifetimes in organolead trihalide perovskites. Adv. Mater. 26, 1584-1893. https://doi.org/10.1002/adma.201305172 (2013).

11. Hui-Seon, K. et al. Mechanism of carrier accumulation in Perovskite thin-absorber solar cells. Nat. Commun. 4, 1-7. https://doi. org/10.1038/ncomms3242 (2013). 
12. Michael, G., René, A., David, B. M. \& Edward, H. S. Materials interface engineering for solution-processed photovoltaics. Nature 488, 304-312. https://doi.org/10.1038/nature11476 (2012).

13. Henry, J. S. Perovskites: The emergence of a new era for low-cost, high-efficiency solar cells. J. Phys. Chem. Lett. 4, 3623-3630. https://doi.org/10.1021/jz4020162 (2013).

14. Burschk, J. et al. Sequential deposition as a route to high-performance perovskite-sensitized solar cells. Nature 499, 316-319. https://doi.org/10.1038/nature12340 (2013).

15. Jeong-Hyeok, I., In-Hyuk, J., Norman, P., Michael, G. \& Nam-Gyu, P. Growth of $\mathrm{CH}_{3} \mathrm{NH}_{3} \mathrm{PbI}_{3}$ cuboids with controlled size for high-efficiency perovskite solar cells. Nat. Nanotechnol. 9, 927-932. https://doi.org/10.1038/nnano.2014.181 (2014).

16. Jeon, N. J. et al. Solvent engineering for high-performance inorganic-organic hybrid perovskite solar cells. Nat. Mater. 13, 897-903. https://doi.org/10.1038/nmat4014 (2014).

17. Nam, J. J. et al. Compositional engineering of perovskite materials for high-performance solar cells. Nature 517, 476-480. https:// doi.org/10.1038/nature14133 (2015).

18. Woon, S. Y. et al. High-performance photovoltaic perovskite layers fabricated through intramolecular exchange. Science 348, 1234-1237. https://doi.org/10.1126/science.aaa9272 (2015).

19. Liu, M., Johnston, M. B. \& Snaith, H. J. Efficient planar heterojunction perovskite solar cells by vapour deposition. Nature 501, 396-403. https://doi.org/10.1038/nature12509 (2013).

20. Xiong, L. et al. A vacuum flash-assisted solution process for high-efficiency large-area perovskite solar cells. Science 353, 58-62. https://doi.org/10.1126/science.aaf8060 (2016).

21. Hui-Seon, K. \& Nam-Gyu, P. Parameters affecting I-V hysteresis of $\mathrm{CH}_{3} \mathrm{NH}_{3} \mathrm{PbI}_{3}$ perovskite solar cells: Effects of perovskite crystal size and mesoporous $\mathrm{TiO}_{2}$ layer. J. Phys. Chem. Lett. 5, 2927-2934. https://doi.org/10.1021/jz501392m (2014).

22. Bo, W. et al. Charge accumulation and hysteresis in perovskite-based solar cells: An electro-optical analysis. Adv. Energy Mater. 5, 1-8. https://doi.org/10.1002/aenm.201500829 (2015).

23. Jin, H. H. et al. Hysteresis-less mesoscopic $\mathrm{CH}_{3} \mathrm{NH}_{3} \mathrm{PbI}_{3}$ perovskite hybrid solar cells by introduction of $\mathrm{Li}$-treated $\mathrm{TiO}_{2}$ electrode. Nano Energy 15, 530-539. https://doi.org/10.1016/j.nanoen.2015.05.014 (2015).

24. Khalid, M., Bhabani, S. S. \& Aram, A. Core-shell heterostructured metal oxide array enable superior light-harvesting and hysteresisfree mesoscopic perovskite solar cells. Nanoscale 7, 12812-12819. https://doi.org/10.1039/C5NR02874D (2015).

25. Kun, C. et al. $\mathrm{MAPbI}_{3-\mathrm{x}} \mathrm{Br}_{\mathrm{x}}$ mixed halide perovskites for fully printable mesoscopic solar cells with enhanced efficiency and less hysteresis. Nanoscale 8, 8839-8846. https://doi.org/10.1039/C6NR01043A (2016).

26. Rohit, D. C. et al. Atomic layer deposition of an effective interface layer of TiN for efficient and hysteresis-free mesoscopic Perovskite solar cells. ACS Appl. Mater. Interfaces 12, 8098-8106. https://doi.org/10.1021/acsami.9b18082 (2020).

27. Do, H. K., Jin, H. H. \& Sang, H. I. Hysteresis-less CsPbI2Br mesoscopic perovskite solar cells with a high open-circuit voltage exceeding $1.3 \mathrm{~V}$ and $14.86 \%$ of power conversion efficiency. ACS Appl. Mater. Interfaces 11, 12123-12131. https://doi.org/10.1021/ acsami.9b03413 (2019).

28. Iwan, Z. et al. Improved efficiency and reduced hysteresis in ultra-stable fully printable mesoscopic perovskite solar cells through incorporation of CuSCN into the perovskite layer. J. Mater. Chem. A 7, 8073-8077. https://doi.org/10.1039/C9TA00669A (2019).

29. Chun-Guey, W. et al. High efficiency stable inverted perovskite solar cells without current hysteresis. Energy Environ. Sci. 8, 2725-2733. https://doi.org/10.1039/C5EE00645G (2015).

30. Xingtian, Y., Meidan, Q., Yonglei, X. \& Wenxiu, Q. High efficiency hysteresis-less inverted planar heterojunction perovskite solar cells with a solution-derived $\mathrm{NiO}_{\mathrm{x}}$ hole contact layer. J. Mater. Chem. A 3, 24495-24503. https://doi.org/10.1039/C5TA08193A (2015).

31. Dong, Y. et al. C, Surface optimization to eliminate hysteresis for record efficiency planar perovskite solar cells. Energy Environ. Sci. 9, 3071-3078. https://doi.org/10.1039/C6EE02139E (2016).

32. Kwang-Ho, J., Ja-Young, S., Seonhee, L., Hyunjung, S. \& Nam-Gyu, P. Solution-processed SnO2 thin film for a hysteresis free planar perovskite solar cell with a power conversion efficiency of 19.2\%. J. Mater. Chem. A 5, 24790-24803. https://doi.org/10. 1039/C7TA08040A (2017).

33. Dae-Yong, S. et al. Universal approach toward hysteresis-free perovskite solar cell via defect engineering. J. Am. Chem. Soc. 140, 1358-1364. https://doi.org/10.1021/jacs.7b10430 (2018).

34. Mahdi, M. B. et al. p-Type CuI islands on $\mathrm{TiO}_{2}$ electron transport layer for a highly efficient planar-perovskite solar cell with negligible hysteresis. Adv. Energy Mater. 8, 1702235. https://doi.org/10.1002/aenm.201702235 (2018).

35. Junwoo, L. et al. Green-solvent-processable, dopant-free hole-transporting materials for robust and efficient perovskite solar cells. J. Am. Chem. Soc. 139, 12175-12181. https://doi.org/10.1021/jacs.7b04949 (2017).

36. Guan-Woo, K., Gyeongho, K., Mahdi, M. B., Gang-Young, L. \& Taiho, P. Gradated mixed hole transport layer in a perovskite solar cell: Improving moisture stability and efficiency. ACS Appl. Mater. Interfaces 9, 27720-27726. https://doi.org/10.1021/acsami.7b070 71 (2017).

37. Qiao, H. et al. Large-area perovskite nanowire arrays fabricated by large-scale roll-to-roll micro-gravure printing and doctor blading. Nanoscale 8, 5350-5357. https://doi.org/10.1039/C5NR08277C (2016).

38. Xiaotian, H. et al. Wearable large-scale perovskite solar-power source via nanocellular scaffold. Adv. Mater. 29, 1-8. https://doi. org/10.1002/adma.201703236 (2017).

39. Fei, Y. et al. Low-temperature soft-cover deposition of uniform large-scale perovskite films for high-performance solar cells. $A d v$. Mater. 29, 1-6. https://doi.org/10.1002/adma.201701440 (2017).

40. Zahra, S., Mahdi, M. B., Nima, T., Mayank, K. \& Michael, S. Solution-processed perovskite thin-films: the journey from lab- to large-scale solar cells. Energy Environ. Sci. 14, 5690-5722. https://doi.org/10.1039/D1EE02018H (2021).

41. Zhao, J. et al. Self-encapsulating thermostable and air-resilient semitransparent perovskite solar cells. Adv. Energy Mater. 7, 1-8. https://doi.org/10.1002/aenm.201602599 (2017).

42. Rongrong, C. et al. Design and understanding of encapsulated perovskite solar cells to withstand temperature cycling. Energy Environ. Sci. 11, 144-150. https://doi.org/10.1039/C7EE02564E (2018).

43. Mahdi, M. et al. Encapsulation strategies for highly stable perovskite solar cells under severe stress testing: Damp heat, freezing, and outdoor illumination conditions. ACS Appl. Mater. Interfaces 13, 45455-45464. https://doi.org/10.1021/acsami.1c11628 (2021).

44. Xiaobo, Z. et al. Rapid degradation behavior of encapsulated perovskite solar cells under light, bias voltage or heat fields. Nanoscale Adv. 3, 6128-6137. https://doi.org/10.1039/D1NA00495F (2021).

45. Andrew, J. P. et al. Oxygen degradation in mesoporous $\mathrm{Al}_{2} \mathrm{O}_{3} / \mathrm{CH}_{3} \mathrm{NH}_{3} \mathrm{PbI}_{3-x} \mathrm{Cl}_{x}$ Perovskite solar cells: Kinetics and mechanisms. Adv. Energy Mater. 6, 1-10. https://doi.org/10.1002/aenm.201600014 (2016).

46. Bert, C. et al. The impact of precursor water content on solution processed organometal halide perovskite films and solar cells. J. Mater. Chem. A. 3, 19123-19128. https://doi.org/10.1039/C5TA06199G (2015).

47. Philip, S. Interface design for metal halide perovskite solar cells. ACS Energy Lett. 3, 1287-1293. https://doi.org/10.1021/acsen ergylett.8b00404 (2018).

48. Nakita, K. N. et al. Enhanced photoluminescence and solar cell performance via lewis base passivation of organic-inorganic lead halide Perovskites. ACS Nano 8, 9815-9821. https://doi.org/10.1021/nn5036476 (2014).

49. Bhumika, C. et al. Poly(4-Vinylpyridine)-based interfacial passivation to enhance voltage and moisture stability of lead halide perovskite solar cells. Chemsuschem 10, 2473-2479. https://doi.org/10.1002/cssc.201700271 (2017). 
50. Lijian, Z. et al. Polymer-modified halide perovskite films for efficient and stable planar heterojunction solar cells. Sci. Adv. 3, 1-11. https://doi.org/10.1126/sciadv.1700106 (2017).

51. Ye, W. et al. Interface engineering of high-performance Perovskite photodetectors based on $\mathrm{PVP} / \mathrm{SnO}_{2}$ electron transport layer. ACS Appl. Mater. Interfaces 10, 6505-6512. https://doi.org/10.1021/acsami.7b18511 (2018).

52. Cong-Cong, Z. et al. Passivated perovskite crystallization and stability in organic-inorganic halide solar cells by doping a donor polymer. J. Mater. Chem. A. 5, 2572-2579. https://doi.org/10.1039/C6TA08970D (2017).

53. Heetae, Y., Seong, M. K., Jong-Kwon, L. \& Mansoo, C. Hysteresis-free low-temperature-processed planar perovskite solar cells with 191\% efficiency. Energy Environ. Sci. 9, 2262-2266. https://doi.org/10.1039/C6EE01037G (2016).

54. Antonio, A. et al. Graphene-Perovskite solar cells exceed 18\% efficiency: A stability study. Chemsuschem 9, 2609-2619. https:// doi.org/10.1002/cssc.201600942 (2016).

55. Dongqin, B. et al. Polymer-templated nucleation and crystal growth of perovskite films for solar cells with efficiency greater than 21\%. Nat. Energy 1, 1-5. https://doi.org/10.1038/nenergy.2016.142 (2016).

56. Mahdi, M. B. et al. Chemical vapor deposited polymer layer for efficient passivation of planar perovskite solar cells. J. Mater. Chem. A 8, 20122-32. https://doi.org/10.1039/D0TA06646J (2020).

57. Ochoa-M, E. et al. Physical passivation of grain boundaries and defects in Perovskite solar cells by an isolating thin polymer. ACS Energy Lett. 6, 2626-2634. https://doi.org/10.1021/acsenergylett.1c01187 (2021).

58. Tomas, L. et al. S, Overcoming ultraviolet light instability of sensitized $\mathrm{TiO}_{2}$ with meso-superstructured organometal tri-halide perovskite solar cells. Nat. Commun. 4, 1-8. https://doi.org/10.1038/ncomms3885 (2013).

59. Jian, Q. et al. Chlorine incorporation for enhanced performance of planar perovskite solar cell based on lead acetate precursor. Appl. Mater. Interfaces 7, 23110-23116. https://doi.org/10.1021/acsami.5b06819 (2015).

60. Giles, E. E. et al. The importance of moisture in hybrid lead halide perovskite thin film fabrication. ACS Nano 9, 9380-9393. https:// doi.org/10.1021/acsnano.5b03626 (2015).

61. Ziyi, W. et al. Influence of hydration water on $\mathrm{CH}_{3} \mathrm{NH}_{3} \mathrm{PbI}_{3}$ perovskite films prepared through one-step procedure. Opt. Express 24, A1431-A1443. https://doi.org/10.1364/OE.24.0A1431 (2016).

62. Binbin, W. et al. Room-temperature water-vapor annealing for high-performance planar perovskite solar cells. J. Mater. Chem. A 4, 17267-17273. https://doi.org/10.1039/C6TA08655A (2016).

63. Yuanhang, C. et al. 18\% High-efficiency air-processed perovskite solar cells made in a humid atmosphere of 70\% RH. Sol. RRL 1, 1-8. https://doi.org/10.1002/solr.201700097 (2017).

64. Yaoguang, R. et al. Synergy of ammonium chloride and moisture on perovskite crystallization for efficient printable mesoscopic solar cells. Nat. Commun. 8, 1-8. https://doi.org/10.1038/ncomms14555 (2017).

65. Dianyi, L. et al. Aqueous-containing precursor solutions for efficient perovskite solar cells. Adv. Sci. 5, 1-7. https://doi.org/10.1002/ advs.201700484 (2018).

66. Menglin, L. et al. Comparison of processing windows and electronic properties between $\mathrm{CH}_{3} \mathrm{NH}_{3} \mathrm{PbI}_{3}$ perovskite fabricated by one-step and two-step solution processes. Org. 63, 159-165. https://doi.org/10.1016/j.orgel.09.011 (2018).

\section{Acknowledgements}

This work was supported by the National Research Foundation of Korea (NRF) grant funded by the Korea government (MSIT) (2020R1A2C1011764, 2020R1A6A3A13075585).

\section{Author contributions}

$\mathrm{J}-\mathrm{HB}$ and $\mathrm{RHJ}$ conceived this project. J-HB evaluated the experimental results as well as did data analysis. DIK performed the whole experiments. JWL, RHJ measured the PL, UV-Vis-NIS, XRD and SEM, respectively. DIK, $\mathrm{RHJ}$ and J-HB wrote the manuscript, and all other authors contributed to the edits of the manuscript.

\section{Competing interests}

The authors declare no competing interests.

\section{Additional information}

Correspondence and requests for materials should be addressed to J.-H.B.

Reprints and permissions information is available at www.nature.com/reprints.

Publisher's note Springer Nature remains neutral with regard to jurisdictional claims in published maps and institutional affiliations.

Open Access This article is licensed under a Creative Commons Attribution 4.0 International format, as long as you give appropriate credit to the original author(s) and the source, provide a link to the Creative Commons licence, and indicate if changes were made. The images or other third party material in this article are included in the article's Creative Commons licence, unless indicated otherwise in a credit line to the material. If material is not included in the article's Creative Commons licence and your intended use is not permitted by statutory regulation or exceeds the permitted use, you will need to obtain permission directly from the copyright holder. To view a copy of this licence, visit http://creativecommons.org/licenses/by/4.0/.

(C) The Author(s) 2022 